\title{
Extracorporeal membrane oxygenation improves coagulopathy in an experimental traumatic hemorrhagic model
}

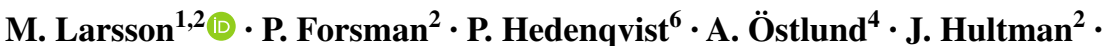 \\ A. Wikman ${ }^{5}$ L. Riddez ${ }^{1,3}$ - B. Frenckner ${ }^{2}$ M. Bottai ${ }^{7}$ C.-M. Wahlgren ${ }^{1,3}$
}

Received: 25 March 2016 / Accepted: 20 July 2016 / Published online: 4 November 2016

(C) The Author(s) 2016. This article is published with open access at Springerlink.com

\begin{abstract}
Purpose Hemorrhage is the most common cause of preventable death after trauma. Coagulopathy plays a central role in uncontrolled bleeding and is caused by multiple factors. Extracorporeal Membrane Oxygenation (ECMO) is an established treatment for patients with respiratory failure and has in recent years also been used in severely injured trauma patients with cardiopulmonary failure and coexisting bleeding shock. The aim of this study was to evaluate the effect of ECMO on hypothermia, acidosis, and coagulopathy in a traumatic hemorrhagic rabbit model.

Methods After anesthesia and tracheostomy, ten New Zealand White rabbits sustained laparotomy, bilateral femur fractures
\end{abstract}

M. Larsson

magnus.larsson@karolinska.se

1 Department of Molecular Medicine and Surgery, Karolinska Institutet and University Hospital, SE-171 76 Stockholm, Sweden

2 ECMO Department Karolinska University Hospital, Karolinska Institutet and University Hospital, SE-171 76 Stockholm, Sweden

3 Department of Vascular Surgery/Trauma Center, Karolinska Institutet and University Hospital, SE-171 76 Stockholm, Sweden

4 Department of Anesthesiology and Intensive Care, Karolinska Institutet and University Hospital, SE-171 76 Stockholm, Sweden

5 Department of Clinical Immunology and Transfusion Medicine, Karolinska Institutet and University Hospital, SE-171 76 Stockholm, Sweden

6 Department of Clinical Sciences, Swedish University of Agricultural Sciences, SE-750 07 Uppsala, Sweden

7 Unit of Biostatistics, Institute of Environmental Medicine, Karolinska Institutet, Stockholm, Sweden and were hemorrhaged $45 \%$ of their estimated blood volume. After $90 \mathrm{~min}$ of hemorrhagic shock they were resuscitated with a standard transfusion protocol together with venoarterial ECMO $(n=5)$ or with a standard transfusion protocol only $(n=5)$ for $60 \mathrm{~min}$. No systemic heparin was administered.

Results ECMO during 60 min of resuscitation significantly increased heart rate $(p=0.01)$, mean arterial pressure $(p=0.01)$, body temperature $(p=0.01)$ and improved the metabolic acidosis, $\mathrm{pH}(p=0.01)$, and lactate $(p=0.01)$. ECMO also improved the coagulation capacity measured in vitro by Rotational Thromboelastometry with a significant decrease in clot formation time $(p<0.01)$. This finding was confirmed in vivo with a significant reduction in the animals' ear bleeding time $(p<0.01)$ and cuticle bleeding time $(p<0.01) ; 5 / 5$ animals survived in the ECMO group and $3 / 5$ animals survived in the control group.

Conclusions Heparin-free ECMO stabilizes circulation, improves coagulation, and may impact short-time survival, during the first $60 \mathrm{~min}$, in an experimental traumatic model with severe hemorrhagic shock.

Keywords Trauma $\cdot$ Shock $\cdot$ Coagulopathy $\cdot$ Animal model $\cdot$ Extracorporeal circulation $\cdot$ ECMO $\cdot$ Hemorrhage . Resuscitation

\section{Introduction}

Major trauma is the leading cause of death worldwide in the young population. Hemorrhage is the most common preventable cause of death after trauma and accounts for up to $30-40 \%$ of trauma-related deaths [1-4]. Early resuscitation emphasizes adequate ventilation, damage control surgery (DCS) with rapid control of bleeding, blood transfusion, and prevention or early management of coagulopathy $[5,6]$. 
Acute traumatic coagulopathy (ATC) is multifactorial, involves the whole process of hemostasis, and is associated with severe injury. Six key factors for initiation of ATC have been identified. They are tissue trauma, shock, hemodilution, hypothermia, acidosis, and inflammation [7]. Tissue injury needs to be combined with hypoperfusion of organs to induce ATC [8]. Acidosis is mainly the result of hypoperfusion and impairs the function of clotting factors. Hypothermia and metabolic acidosis are late effects of bleeding shock and clearly enhance coagulopathy. Acidosis and hypothermia do not seem to cause clinical relevant effects on protease function until $\mathrm{pH}$ is $<7.2$ and temperatures are under $33{ }^{\circ} \mathrm{C}$. Platelet function and aggregation are reduced at temperatures lower than $35{ }^{\circ} \mathrm{C}$ [9-12]. Extracorporeal Membrane Oxygenation (ECMO) has been an established treatment for severe respiratory failure for more than 20 years $[13,14]$. ECMO treatment in trauma patients with severe hypoxia due to pulmonary contusions or acute respiratory distress syndrome (ARDS) has previously been described [15]. In severe hemorrhage with hemodynamic compromise ECMO therapy is less well established even though occasional reports on immediate ECMO in multitrauma have been published [16-19].

This is a proof-of-concept study and the aim was to investigate if venoarterial ECMO (VA-ECMO) could reverse acidosis, hypothermia, and coagulopathy in a traumatic hemorrhagic rabbit model during the initial 60 min of resuscitation.

\section{Materials and methods}

\section{Study animals and control group}

15 male New Zealand White rabbits (mean weight $3.85 \mathrm{~kg}$ ) were used in an experimental trauma model with bilateral femur fractures, laparotomy, and a class IV bleeding shock ( $>40 \%$ hemorrhage of blood volume) (Fig. 1). Five rabbits, the control group, were treated with a standard transfusion protocol meaning transfusion of citrated whole blood, calcium, and active rewarming. Another five rabbits, the ECMO group, received the same treatment as the former group but were also on venoarterial ECMO (VA-ECMO) for $60 \mathrm{~min}$ (Fig. 2). Finally, five rabbits were used as blood donors for priming the ECMO-circuits (one rabbit/circuit). All rabbits were siblings with blood group B. The ECMO model was previously developed and used [20].

\section{Outcomes}

The primary outcomes were coagulation status, $\mathrm{pH}$, lactate, base excess, and body temperature after $60 \mathrm{~min}$ of resuscitation. Secondary outcomes were heart rate, mean arterial pressure, and short-term survival.

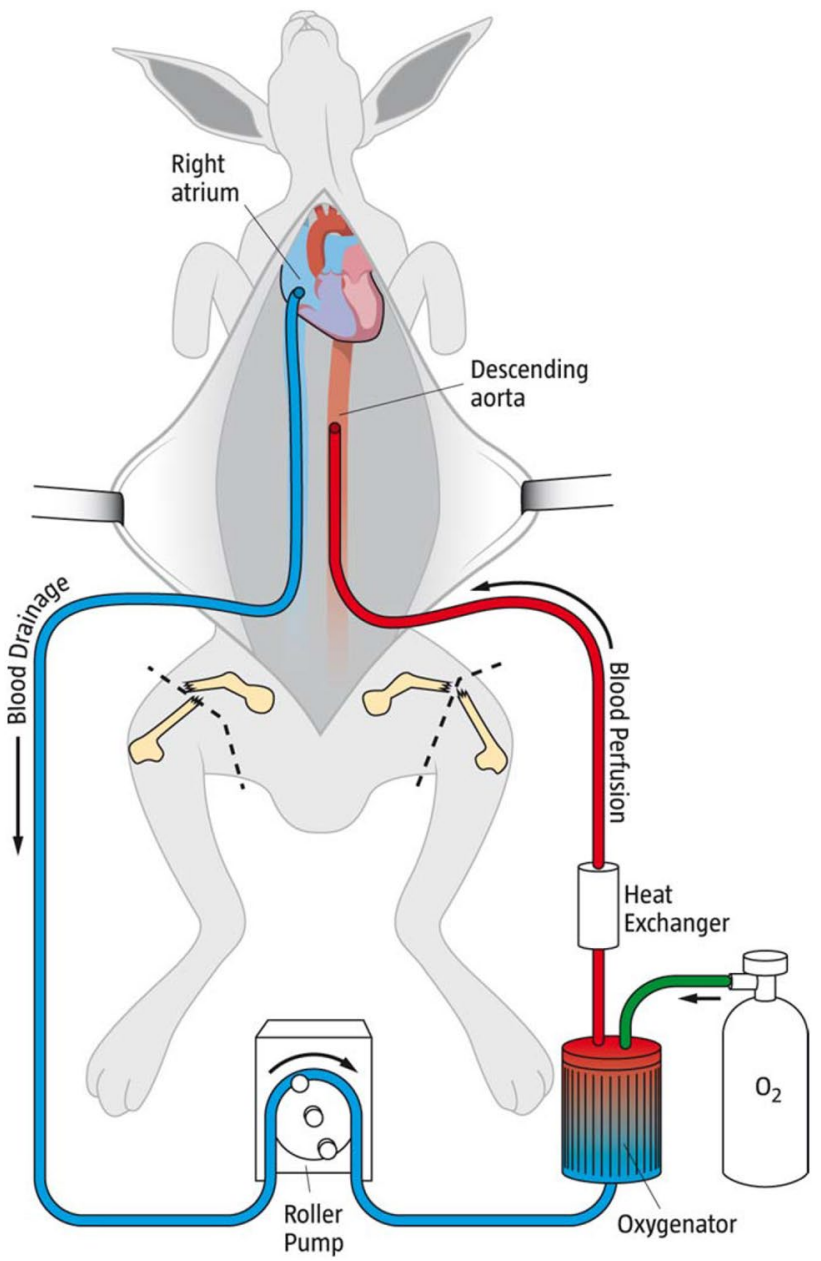

Fig. 1 The Rabbit ECMO-Trauma model. The animal sustained laparotomy and bilateral femur fractures and were exsanguinated to class IV Shock. The venoarterial ECMO circuit: Venous draining cannulae in the right atrium (blue), roller pump, heparinized membrane oxygenator for saturation and carbondioxide removal, water heat exchanger $\left(38.5^{\circ} \mathrm{C}\right)$. Blood is reinfused in the descending aorta $(r e d)$. Bilateral femurfractures are indicated

\section{Anesthesia}

For premedication medetomidine $(0.2 \mathrm{mg} / \mathrm{kg})$ was administered subcutaneously. Total intravenous anesthesia (TIVA) was performed with sufentanil $(6.9 \mathrm{mg} / \mathrm{kg}$ per hour and midazolam $(1.35 \mathrm{mg} / \mathrm{kg}$ per hour). Before initiation of the femur fractures, the TIVA was changed to ketamine infusion $(12.5-25 \mathrm{mg} / \mathrm{kg} / \mathrm{h})$ for the remainder of the experiment. No neuromuscular blocking agents were used.

\section{Instrumentation}

Percutaneous venous catheters were placed in both ears for administration of drugs. An arterial line was placed in the right ear artery for blood pressure monitoring before the hemorrhage phase in both groups and during the 


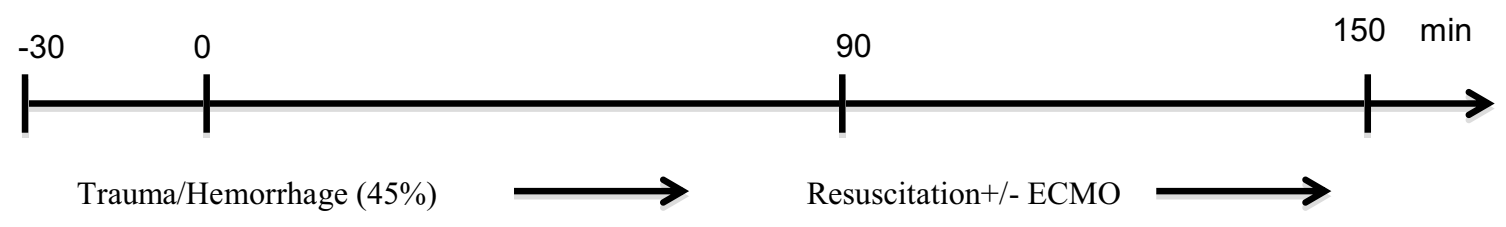

Fig. 2 Flowchart illustrating the study's timeline. Induction of anesthesia was at $-30 \mathrm{~min}$. All rabbits (n10) sustained laparotomy and femurfractures at baseline, $0 \mathrm{~min}$. During $30 \mathrm{~min}$ blood was drained from the IVC. The animals were kept in bleeding shock for another $60 \mathrm{~min}$ (goals were mean arterial pressure $<20 \mathrm{mmHg}$, tempera-

resuscitation phase in the ECMO group. $5 \mathrm{Fr}$ introducers were placed in the inferior vena cava (IVC) and descending aorta (DA). The vessels were cannulated for blood drainage and potential connection to an ECMO system. Arterial pressure was controlled in the DA during the hemorrhage phase in both groups and during the resuscitation phase in the control group. If the animal was to be treated with VAECMO, the IVC was cannulated with a 12 Fr Fem-Flex II venous cannula (Edwards Lifesciences ${ }^{\mathrm{TM}}$ ) with the tip in the right atrium of the heart. The DA was cannulated with the tip pointing towards the heart with an 8 Fr Fem-Flex II arterial cannula (Edwards Lifesciences ${ }^{\mathrm{TM}}$ ) (Fig. 1).

\section{Ventilation and ECMO}

The animals were tracheotomized with a $3.5 \mathrm{~mm}$ cuffed endotracheal tube and put on pressure controlled mechanical ventilation with $25-30 \%$ oxygen, $8-15$ breaths/min with $4 \mathrm{cmH}_{2} \mathrm{O}$ post end expiratory pressure (PEEP) and peak pressure of $20 \mathrm{cmH}_{2} \mathrm{O}$ (Servo $900 \mathrm{C}^{\circledR}$, Siemens-Elema). Repeated blood gas analyses were performed (ABL 800, Radiometer) and ventilation was adjusted accordingly aiming for normoventilation before trauma was induced.

The ECMO circuit was custom-made and consisted of a Stöckert ${ }^{\circledR}$ roller pump, a Medos ${ }^{\circledR}$ Hilite LT Infant 800 oxygenator and $1 / 4$ " surface-heparinized standard tubings of 200 $\mathrm{cm}$ length. The blood was warmed $38.5{ }^{\circ} \mathrm{C}$ using a waterfilled heat exchanger (HICO-Aquaterm 660, Hirtz). The ECMO systems were primed with $120 \mathrm{ml}$ of citrated blood from the donor rabbits. Citrate ratio: 1 part sodium citrate $2.63 \mathrm{~g} / \mathrm{L}$ (Macopharma $\left.{ }^{\circledR}\right) / 12$ parts blood). No heparin was added and no transfusion reactions were observed. Sweep gas flow over the oxygenator was set on $\mathrm{O}_{2} 1000 \mathrm{ml} / \mathrm{min}$ and $\mathrm{CO}_{2} 50 \mathrm{ml} / \mathrm{min}$, to inhibit elimination of $\mathrm{CO}_{2}$ over the oxygenator (Fig. 1).

\section{Monitoring}

The animals were monitored continuously with electrocardiogram (ECG); mean arterial pressure (MAP), esophageal temperature, saturation of the tongue and end-tidal $\mathrm{CO}_{2}$. ture $<32{ }^{\circ} \mathrm{C}$, and $\left.\mathrm{pH}<7.3\right)$. At 90 min resuscitation began with a standard protocol $(n=5)$ or with a standard protocol and venoarterial ECMO in addition $(n=5)$. Rotational thromboelastometry and standard coagulation tests were controlled at 0,90 and $150 \mathrm{~min}$. The animals were killed at $150 \mathrm{~min}$

\section{Traumatic hemorrhage phase}

The rabbits initially sustained midline laparotomies and bilateral femur fractures. The fractures were located centrally on both femurs using two small pipe wrenches with a distance of $2 \mathrm{~cm}$. By fixating both ends of the femurs with the pipe wrenches and moving the wrenches shafts apart, mid-shaft femur fractures were induced on both sides of each study animal. $45 \%$ of the rabbits estimated blood volume $(70 \mathrm{ml} / \mathrm{kg})$ was drawn with syringes from the IVC continuously during $30 \mathrm{~min}$. The drained blood was citrated (ratio 1/12) and stored in a blood warmer at $38.5^{\circ} \mathrm{C}$. The animals were kept in hemorrhagic shock for an additional 60 min. Ringer's solution was infused to keep the MAP at approximately $20 \mathrm{mmHg}$, a temperature of less than $32{ }^{\circ} \mathrm{C}$ and a $\mathrm{pH}$ below 7.3. The total hemorrhagic shock time was 90 min (Fig. 2).

\section{Resuscitation phase}

After the traumatic hemorrhage shock phase, the resuscitation phase started. The control group was transfused during $30 \mathrm{~min}$ with warm citrated blood $\left(38.5^{\circ} \mathrm{C}\right)$, followed by rewarming with a heating mattress for another $30 \mathrm{~min}$. If calcium levels fell below $1.0 \mathrm{mmol} / \mathrm{L}$, calcium was substituted (Calcium Sandoz ${ }^{\circledR}$ ).The ECMO group received the same treatment as the control group and VA-ECMO with a flow rate of $100 \mathrm{ml} / \mathrm{kg} / \mathrm{min}$ for $60 \mathrm{~min}$, in addition (Figs. 1, $2)$. At the end of the experiment $(150 \mathrm{~min})$ all animals were killed in deep anesthesia with Pentobarbitalnatrium ${ }^{\circledR}$ $120 \mathrm{mg} / \mathrm{kg}$ (Fig. 2).

\section{Blood chemistry and coagulation status}

Blood-gasses were drawn every $15 \mathrm{~min}$ and analyzed immediately for $\mathrm{pH}, \mathrm{pCO}_{2}, \mathrm{pO}_{2}$, Base Excess (BE), Hemoglobin, Hematocrit, $\mathrm{K}^{+}, \mathrm{Na}^{+}, \mathrm{Ca}^{2+}, \mathrm{Cl}^{-}$, Glucose, and Lactate.

At baseline (0 min), after 90 min of hemorrhagic shock and after $60 \mathrm{~min}$ of resuscitation, or when it was obvious that asystole was to occur within minutes, the following 
coagulation tests were controlled-activated partial thromboplastin time (aPTT), D-dimer, fibrinogen concentration, fibrin, prothrombincomplex(PT)/international normalized ratio (INR), platelet count (PLT), and ROTEM.

\section{Rotem}

The ROTEM ${ }^{\circledR}$ analyses were performed on whole blood, collected in tubes containing $0.129 \mathrm{~mol} \mathrm{l}^{-1}$ sodium citrate and analyzed according to manufacturer's instruction ROTEM $^{\circledR}$ Delta 3000 (TEM innovations, GmbH, München, Germany). Analyses were performed within $30 \mathrm{~min}$ at a temperature adjusted to the actual rabbit's body temperature. The variables analyzed in ROTEM were extrinsic pathway (EXTEM) and intrinsic pathway (INTEM). Clotting time (CT) reflected the time until initiation of a clot. Clot formation time (CFT) reflected the time until a $4 \mathrm{~mm}$ clot was formed. EXTEM maximum clot firmness (MCF) reflected the stability of the clot. Fibrinogen function (FIBTEM) and heparin effect (HEPTEM) were also analyzed.

\section{Bleeding time}

In vivo bleeding times were controlled at baseline, at the end of resuscitation or prior to asystole. Bleeding time was controlled as follows. The animals' Ear Bleeding Time (EBT) was tested with Surgicut ${ }^{\circledR} \mathrm{Jr}$ (SUJ 50i) and blotting paper in both ears [21]. The cuticle bleeding time (CBT) was also measured with a standardized incision in the second digit of the right front foot by cutting the claw with a sharp nail clipper, including the apex of the cuticle, thereby inducing a combined arterial and venous bleeding [22].

\section{Statistical analyses}

The statistical analyses were made by the Biostatistics Core Facility, Karolinska Institutet. All the outcome variables described in the above subsections were considered. The outcome variables were analyzed one at a time. Each outcome variable was compared between the two treatment arms over the study follow-up period from baseline to $150 \mathrm{~min}$. For each outcome variable, the mean value was estimated over follow-up time and by treatment arm with a linear regression model that included minutes since intervention as categorical variable, the binary indicator for treatment, and all pair-wise interaction terms. The standard errors were obtained with a cluster robust estimator that took the within animal dependence into account [23]. The animals represented the clusters. The estimated means and 95\% confidence intervals are reported in the figures. The differences between means of outcome variable at $90 \mathrm{~min}$ and at $150 \mathrm{~min}$ were obtained from the robust regression models. In addition, the distribution of each outcome variable at $90 \mathrm{~min}$ and $150 \mathrm{~min}$ was tested with the Wilcoxon's rank-sum test.

\section{Results}

\section{Traumatic hemorrhage phase}

After traumatic injury and $90 \mathrm{~min}$ of hemorrhagic shock, all animals $(n=10)$ were in a critical state with bradycardia $(<100 \mathrm{bpm})$ and fulfilled the set criteria of hypotension (MAP $\leq 20 \mathrm{mmHg}$ ), hypothermia $\left(T<32^{\circ} \mathrm{C}\right.$ ), metabolic acidosis ( $\mathrm{pH}<7.3$ ), and coagulopathy (ROTEM clot amplitude $<35 \mathrm{~mm}$ at $5 \mathrm{~min}$ ). There was no significant difference in acidemia ( $\mathrm{pH}, \mathrm{pCO}_{2}, \mathrm{BE}$, lactate), temperature, hemodynamic status (HR and MAP) or ROTEM between the two groups after the $90 \mathrm{~min}$ of traumatic hemorrhage. The hematocrit did not differ between the two groups after hemorrhage and resuscitation (Fig. 3).

\section{Resuscitation phase}

\section{Hemodynamic status}

Immediately after initiation of ECMO, the HR and MAP improved and after $60 \mathrm{~min}$ the animals were close to a normal circulatory state. After resuscitation in the control group the HR and MAP increased during the first 30 min. MAP never exceeded $40 \mathrm{mmHg}$ and then decreased again. There was a significant difference in MAP, favoring the ECMO group, after $60 \mathrm{~min}$ of resuscitation (Fig. 4). Although no specific immune testing of the blood was performed, no signs of adverse effects of the allogeneic blood transfusions were observed.

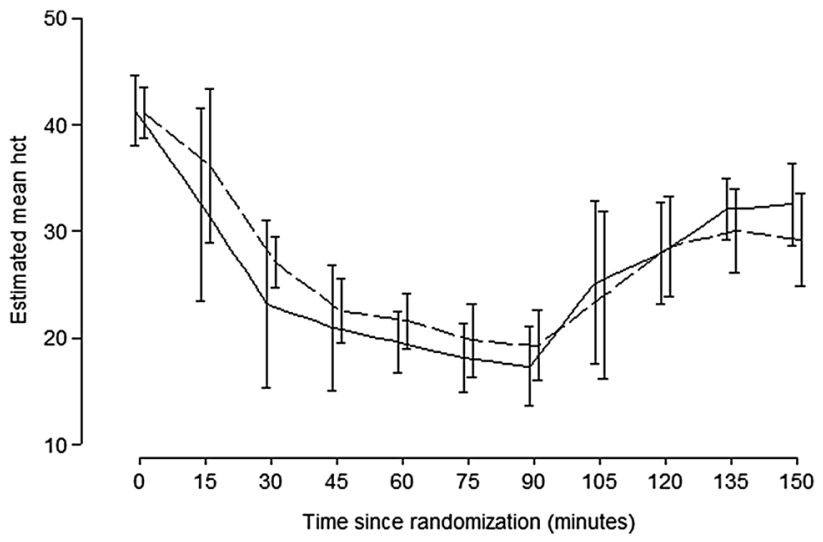

Fig. 3 The Hematocrit during the study. The exsanguination and transfusion in the two groups were equal. Control (solid line) ECMO (dashed line) 


\section{Ventilation and ECMO}

The animals were equally saturated in both groups during baseline and hemorrhage. After resuscitation and before circulatory arrest $\mathrm{pO}_{2}$ in the control group was above normal (mean $27.0 \mathrm{kPa}$ ) due to increased oxygen in the ventilator. No arterial blood gas was performed in ECMO group due to a lack of central arterial access and no AV-bridge in the circuit. Instead pre-oxygenator blood gas was drawn reflecting the rabbit's respiratory status and acid-base status. The $\mathrm{pCO}_{2}$ (Table 1) was equal in the two groups, both at the end of the hemorrhage phase and after resuscitation. A limited stable ECMO flow of $100 \mathrm{ml} / \mathrm{min}$ was obtained.

\section{Acid-base balance}

There was a significant fall in $\mathrm{pH}$, decrease in $\mathrm{BE}$, and rise in lactate, in both groups during the traumatic hemorrhage phase (Fig. 5a, b; Table 1). The lactate concentration slowly started to fall with ECMO but continued to rise in the control group after resuscitation. At the end of the resuscitation phase lactate was significantly lower in the ECMO group. After $15 \mathrm{~min}$ of ECMO, pH started to increase and was over 7.0 after $60 \mathrm{~min}$. Meanwhile the $\mathrm{pH}$ continued to deteriorate in the control group. The difference in $\mathrm{pH}$ between the two groups after $60 \mathrm{~min}$ reached statistical significance. Base Excess started to increase after $30 \mathrm{~min}$ of ECMO treatment and was overall significantly improved compared to the control group.

\section{Body temperature}

ECMO significantly improved the animal's body temperature and after $60 \mathrm{~min}$ of active warming the temperatures

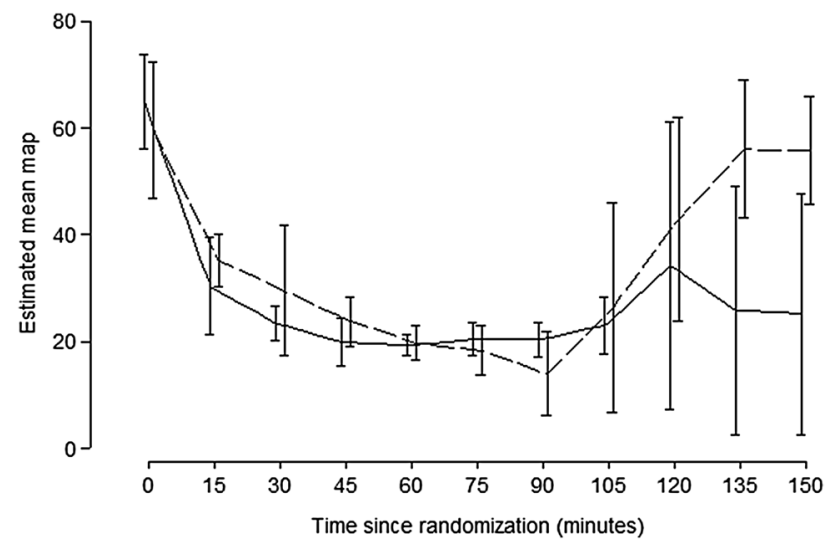

Fig. 4 The animals' mean arterial pressure during the study. At 90 min after hemorrhagic shock there was no difference in mean arterial pressure between the two groups but after $60 \mathrm{~min}$ of resuscitation the mean arterial pressure in the ECMO group was significantly improved ( $p=0.01$ respectively). Control (solid line) ECMO (dashed line) were almost normalized $\left(>37^{\circ} \mathrm{C}\right)$. The body temperatures remained low (below $30^{\circ} \mathrm{C}$ ) in the control group (Fig. 5c).

\section{Coagulation in vitro (Table 1)}

The contact pathway of coagulation was evaluated with aPTT and ROTEM Clotting Time, $\mathrm{CT}_{\text {Intem }}$. The aPTT decreased in the ECMO group during the 60 min of resuscitation, while aPTT, in the control group, continued to rise. The difference between the two groups did not reach statistical significance. $\mathrm{CT}_{\text {Intem }}$ increased in both groups, but even though there was no significant difference at the end of resuscitation, the rise was higher in the control group.

The tissue factor dependent extrinsic pathway of coagulation was analyzed by INR, ROTEM CT $\mathrm{T}_{\text {Extem, }}$ and $\mathrm{CFT}_{\text {Extem. }}$ INR decreased after 60 min of ECMO while it remained on the same level in the control group.

The extem clotting time $\left(\mathrm{CT}_{\text {Extem }}\right)$ was considerably reduced in the ECMO group, while it was largely prolonged in the control group and there was a difference between the groups at the end of the experiment. The clot formation time $\left(\mathrm{CFT}_{\text {Extem }}\right)$ followed the same pattern and was significantly reduced in the ECMO group after resuscitation.

Analyzing the clot firmness with ROTEM: $\mathrm{MCF}_{\text {Extem }}$ (reflecting both platelet and fibrinogen contribution) was slightly increased after ECMO for $60 \mathrm{~min}$. while it was reduced in the control $(p=0.2)$. The $\mathrm{MCF}_{\mathrm{Fibtem}}$ (only fibrinogen contribution) showed low detectable values at the end of the experiments equally in both groups. The Fibrinogen levels were also equally diminished in the two groups and did not increase after transfusion.

Neither in the study group nor in the control group, did the ROTEM curves show any fibrinolysis. Analyses with HEPTEM, blocking the heparin effect, did not change the INTEM CT or CFT variables. This indicates that the systemic effect of surface heparin was negligible.

The platelet count was equal in the two groups initially but after 90 min of hemorrhagic shock the platelet count was lower in the ECMO group. The number of circulating platelets kept falling and was at the end of the resuscitation phase significantly reduced in the ECMO group compared to the control group.

\section{Coagulation in vivo (Table 1)}

The baseline bleeding times according to EBT and CBT were equal in the two groups. After resuscitation both the difference in EBT and CBT were statistically significant, favoring the ECMO group.

\section{Outcome and survival}

In the ECMO group, three animals (3/5) were asystolic and one was severely bradycardic $(\mathrm{HR}<10)$ at cannulation. 
Table 1 Blood and coagulation

\begin{tabular}{|c|c|c|c|c|c|c|c|}
\hline & Baseline, 0 min & Control, $90 \mathrm{~min}$ & ECMO, 90 min & $P^{1}$ & Control, $150 \mathrm{~min}$ & ECMO, $150 \mathrm{~min}$ & $P^{2}$ \\
\hline Temp $\left({ }^{\circ} \mathrm{C}\right)$ & $38.4 \pm 0.1$ & $30.3 \pm 0.4$ & $30.7 \pm 0.2$ & 0.34 & $29.3 \pm 0.4$ & $37.3 \pm 0.3$ & 0.01 \\
\hline $\mathrm{pH}$ & $7.44 \pm 0.01$ & $7.20 \pm 0.04$ & $7.16 \pm 0.10$ & 0.38 & $6.90 \pm 0.03$ & $7.08 \pm 0.04$ & 0.01 \\
\hline $\mathrm{pCO}_{2}(\mathrm{kPa})$ & $7.11 \pm 0.25$ & $5.90 \pm 0.89$ & $6.13 \pm 0.64$ & 0.75 & $7.02 \pm 0.93$ & $7.48 \pm 0.54$ & 0.46 \\
\hline Lactate $(\mathrm{mM})$ & $1.07 \pm 0.05$ & $11.6 \pm 1.4$ & $8.9 \pm 1.1$ & 0.10 & $14.3 \pm 1.1$ & $7.8 \pm 0.7$ & 0.01 \\
\hline $\mathrm{BE}(\mathrm{mM})$ & $2.79 \pm 0.03$ & $-12.3 \pm 1.8$ & $-14.3 \pm 2.3$ & 0.26 & $-21.4 \pm 0.5$ & $-16.2 \pm 1.0$ & 0.01 \\
\hline $\mathrm{Hb}(\mathrm{g} / \mathrm{L})$ & $134 \pm 3$ & $56 \pm 4$ & $62 \pm 3$ & 0.17 & $90 \pm 16$ & $93 \pm 8$ & 0.45 \\
\hline $\mathrm{PLT} \times 10^{9} / 1$ & $193 \pm 17$ & $131 \pm 23$ & $93 \pm 18$ & 0.17 & $149 \pm 20$ & $85 \pm 17$ & 0.02 \\
\hline aPTT (s) & $14.4 \pm 2.6$ & $20.6 \pm 4.3$ & $17.7 \pm 2.7$ & 0.16 & $29.0 \pm 87$ & $11.0 \pm 23$ & 0.07 \\
\hline INR & $0.9 \pm 0.0$ & $1.3 \pm 0.15$ & $1.74 \pm 0.33$ & 0.20 & $1.36 \pm 0.09$ & $1.44 \pm 0.2$ & 0.42 \\
\hline Fibrinogen (g/l) & $2.2 \pm 0.0$ & $1.2 \pm 0.3$ & $0.9 \pm 0.2$ & 0.38 & $1.3 \pm 0.2$ & $1.0 \pm 0.2$ & 0.38 \\
\hline $\mathrm{CT}_{\mathrm{Ext}}(\mathrm{s})$ & $45 \pm 2$ & $69 \pm 4$ & $764 \pm 687$ & 0.04 & $827 \pm 710$ & $79 \pm 8$ & 0.17 \\
\hline $\mathrm{CFT}_{\mathrm{Ext}}(\mathrm{s})$ & $42 \pm 1$ & $170 \pm 14$ & $1141 \pm 965$ & 0.46 & $1770 \pm 1001$ & $111 \pm 19$ & 0.01 \\
\hline $\mathrm{MCF}_{\mathrm{Ext}}(\mathrm{mm})$ & $66.7 \pm 0.5$ & $51.2 \pm 0.9$ & $42.2 \pm 10.4$ & 0.30 & $35.6 \pm 10.6$ & $51.6 \pm 2.8$ & 0.20 \\
\hline $\mathrm{CT}_{\text {Int }}(\mathrm{s})$ & $181 \pm 28$ & $262 \pm 357$ & $245 \pm 64$ & 0.46 & $948 \pm 693$ & $290 \pm 93$ & 0.34 \\
\hline $\operatorname{MCF}_{\mathrm{Fib}}(\mathrm{mm})$ & $11.3 \pm 0.5$ & $4.0 \pm 0.3$ & $4.2 \pm 1.0$ & 0.33 & $3.4 \pm 1.0$ & $4.8 \pm 1.0$ & 0.19 \\
\hline EBT (s) & $66.0 \pm 9.0$ & - & - & - & $162.0 \pm 21.0$ & $55.5 \pm 7.0$ & 0.01 \\
\hline CBT (s) & $70.5 \pm 10.5$ & - & - & - & $174.0 \pm 15.0$ & $75.0 \pm 13.0$ & 0.01 \\
\hline
\end{tabular}

Baseline represents all animals. The control and ECMO groups are compared after hemorrhagic shock (90 min) and after resuscitation (150 min) and $p$ values are calculated with Rank-Sum Test. $P^{1} 90 \mathrm{~min}, P^{2} 150 \mathrm{~min}$ Values presented as Means with SEM

Temp temperature, $B E$ base excess, $H b$ hemoglobin, $P L T$ platelets, $a P T T$ activated partial thromboplastin time, INR international normalized ratio (a Ratio of Prothrombine Time), $C T_{E x t}$ clotting time extrinsic, $C F T_{E x t}$ clot formation time extrinsic, $M C F_{E x t}$ maximum clot firmness extrinsic, $C T_{\text {Int }}$ clotting time intrinsic, $M C F_{F i b}$ maximum clot firmness fibtem, $E B T$ ear bleeding time, $C B T$ cuticle bleeding time

They all received external cardiac compressions and recovered with recapture of sinus rhythm and normalized blood pressure after initiation of extracorporeal circulation. In summary, all animals (5/5) in the ECMO group survived with stabilized vital status and improved coagulation. Two animals (2/5) in the control group were asystolic, $28 \mathrm{~min}$, respectively, $30 \mathrm{~min}$ after initiation of resuscitation (transfusions were completed in both cases). They received external cardiac compressions but did not regain sinus rhythm. The surviving animals in the control group (3/5) were all severely hypotensive and hypothermic.

\section{Discussion}

Trauma-induced coagulopathy is an important factor for hemorrhagic death in trauma victims [7]. When fully developed, the coagulopathy is very difficult to reverse. This study shows that VA-ECMO improves acidosis and temperature in a traumatic experimental hemorrhagic model. The heater in the ECMO circuit was superior compared to warm transfusions and heating mattress in the control group. ECMO increased the temperature above $37{ }^{\circ} \mathrm{C}$ and increased $\mathrm{pH}$ above 7.0 within $60 \mathrm{~min}$. ECMO also improved central circulation in terms of blood pressure and heart rate. When assisted by VA-ECMO all the animals in severe hemorrhagic shock survived. The extrinsic coagulation pathway reflected by clot formation time $\left(\mathrm{CFT}_{\text {Extem }}\right)$ was improved and there was a trend of improvement in the intrinsic pathway as well. In vivo testing of the coagulation capacity with ear bleeding and cuticle bleeding times showed an improvement in the ECMO group.

To our knowledge no similar study has previously been performed. This rabbit ECMO model was earlier used evaluating the Factor XII antibody 3F7 [20]. ECMO has previously been used in a rabbit-trauma model where ECMOresuscitation for prolonged hemorrhagic shock $(3 \mathrm{~h})$ improved tissue perfusion, reduced systemic inflammation, and alleviated the intestinal damage that may be one important factor for Multi Organ Failure (MOF) [24]. Park et al. showed that rats exposed to both hemorrhagic shock and hypothermia have a prolonged clot formation time and reduced MCF [25]. The former finding is verified by the present results, but ECMO only slightly improved the clots firmness. This may be due to the consumption of fibrinogen. The fibrinogen levels were equally reduced after hemorrhagic shock in both groups and the ECMO system did not seem to aggravate fibrinogen consumption.

Apart from a lower platelet count and much higher $\mathrm{CT}_{\text {Extem }}$ and $\mathrm{CFT}_{\text {Extem }}$ in the ECMO group after hemorrhagic shock there was no difference between the groups before resuscitation. 

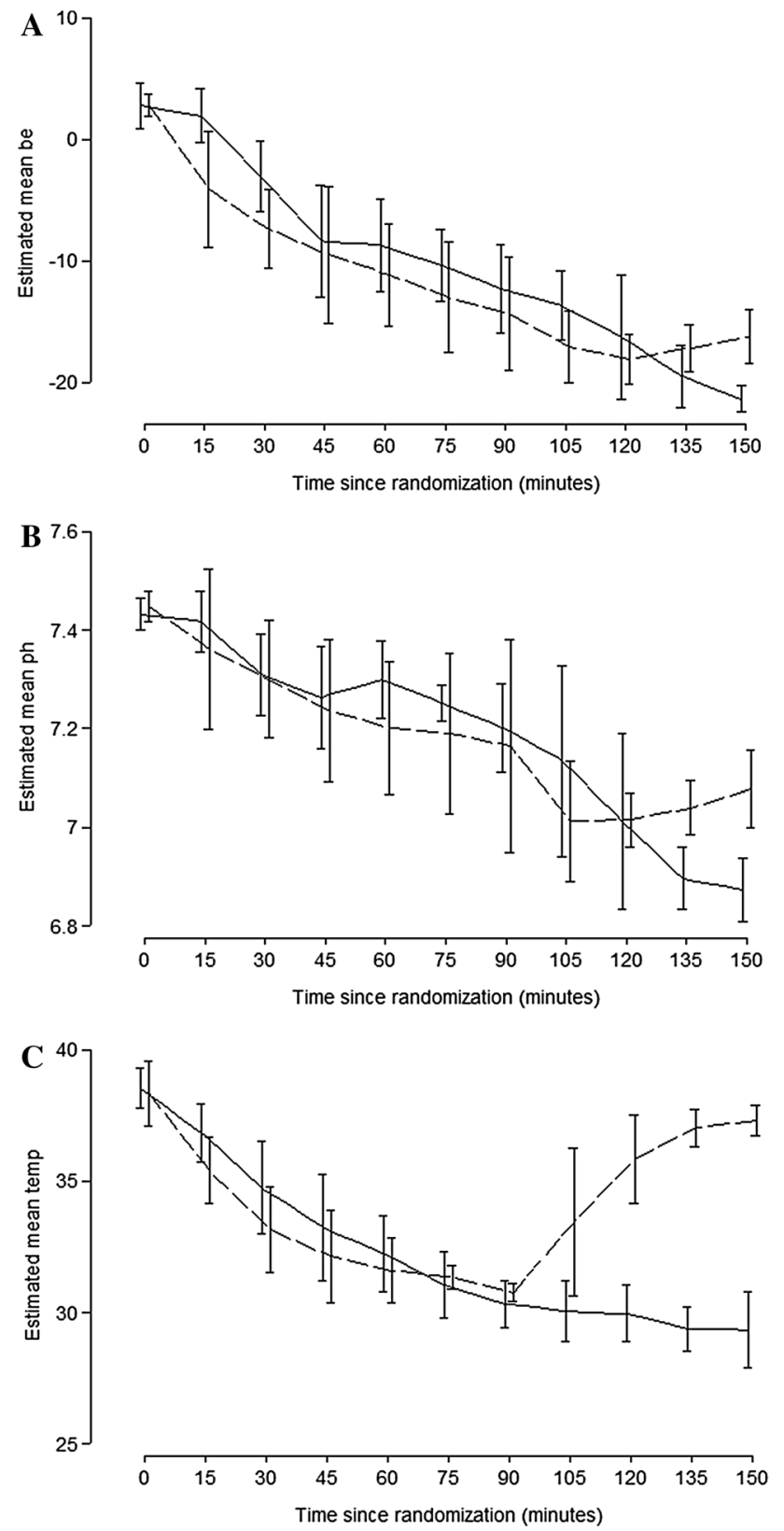

Fig. 5 a, b The animals acid-base balance during the study. 90 min after hemorrhagic shock there was no difference in Base Excess (a) or $\mathrm{pH}$ (b) between the two groups. After $60 \mathrm{~min}$ of resuscitation the Base Excess and the $\mathrm{pH}$ were significantly higher in the ECMO group ( $p=0.01$, respectively). Control (solid line) ECMO (dashed line). c The animals' body temperature. Initiation of ECMO increased the animals body temperature efficiently and after $60 \mathrm{~min}$ the animals in the ECMO group were significantly warmer $\left(>37^{\circ} \mathrm{C}\right)$ than the controls $(p=0.001)$

In spite of the initial advanced coagulopathy, several coagulation parameters improved after ECMO-resuscitation. Engstrom et al. showed the importance of an increased $\mathrm{pH}$ and reduced lactic acidosis to avoid impairment of the coagulation cascade in two previous studies $[12,26]$.
We believe that the improvement of tissue perfusion with ECMO resulted in a gradual normalization of $\mathrm{pH}$ and lactate. This may have had a beneficial effect on the coagulation capacity. To gain efficiently strong clots after this type of trauma it is necessary to substitute fibrinogen. In the present study the fibrinogen was consumed, stayed on a low level and was not substituted. This was verified by a reduction of the maximum clot firmness. These findings suggest that the reduction was mainly due to low fibrinogen levels. In a clinical setting fibrinogen would have been substituted.

Extracorporeal devices activate the coagulation system [27] and previous studies have shown decreased numbers of circulating platelets in extracorporeal devices [28, 29]. This finding was confirmed in the present study. The number of circulating platelets did not reach levels below $50 \times 10^{9} / \mathrm{L}$ and the clotting ability did not seem to be negatively affected. ECMO in trauma has been somewhat controversial but has in recent years gained popularity both in the post-trauma ARDS situation and in hypovolemic shock during the early resuscitation phase [16]. In our clinical experience, we have successfully resuscitated selected patients with respiratory failure and concomitant hemorrhagic shock due to thoraco-abdominal trauma with venoarterial ECMO (unpublished data). In this model no intentional pulmonary injury was induced. $\mathrm{A}$ high $\mathrm{pO}_{2}$ in the control group supports this. ECMO improves both hypoxic metabolic acidosis and hypercapnic respiratory acidosis. In combination with lung injury ECMO may add further positive effects on the traumatic coagulopathy. An earlier experimental study described how VA-ECMO reduced systemic venous pressure while maintaining or improving systemic perfusion in both a normal circulatory state and in the setting of increased right ventricular load associated with acute lung injury [30]. ECMO may theoretically be a useful tool in reducing blood loss during major venous hemorrhage, but other positive or negative effects of ECMO in trauma need to be investigated.

There have been concerns about using heparin in trauma patients on ECMO. We did not use systemic heparin as anticoagulant for the ECMO system but heparinized surfaces of tubings and oxygenators. The blood used for priming the circuit was citrated with the same concentration as blood products that are normally transfused to trauma victims. Calcium was substituted as needed. Viscoelastic heparin test did not show any effect of free heparin in the system. The aPTT were reduced during ECMO treatment but there were no signs of clotting in the circuits. In the future it may be possible to use anticoagulant drugs that do not affect the bleeding risk [20].

Inflammation and coagulation are largely activated in ECMO systems [31]. In this study we did not focus on the immune system or inflammation. The aim was to study the effect of ECMO support on hypothermia, acidosis, and 
coagulopathy in the first initial 60 min of trauma resuscitation. The ability of ECMO to fast increase the body temperature during this time is obvious but the reduction of lactate and improvement of $\mathrm{pH}$ is somewhat slower. If ECMO had been extended for more than $60 \mathrm{~min}$ or even continued for the first 24 post-trauma hours, the acid-base balance might have been improved further. ECMO in trauma may be performed without heparin for at least $24 \mathrm{~h}$.

A low ECMO flow was accepted due to limited drainage. This limitation was caused by hypovolemia and in this study a lack of further transfusion possibilities. In clinical trauma scenarios, continuous bleeding is a common problem which can cause difficulties to withhold a high ECMO flow. However, with the availability of donor blood, the ECMO circuit can quickly be filled with more blood, and the large bore cannulas are optimal for high volume infusion [16].

There are some obvious limitations with our study. The number of study animals is small, especially as in the control group at the end of the study only three animals are left. The posttraumatic observation time was short, only $150 \mathrm{~min}$. The small animal model with rabbits was used because of earlier experience, but a large animal model may have been closer to a human scenario. The coagulation system in rabbits is slightly different compared to humans but their coagulation system is constructed as the human with extrinsic, intrinsic and a common pathway's and consists of the same coagulation factors. Some serin protease activities are different. Rabbits have a 50 times higher activity of factor $\mathrm{V}$ than humans and the activity of factor $\mathrm{XI}$ and factor XIII is also slightly higher. This may explain why rabbits have shorter aPTT and PT [32]. The different activity may limit implications for human management and the variations of our coagulation data may be explained by a limited time of ECMO-resuscitation. Furthermore, it is difficult to simulate a realistic traumatic model with coagulopathy in animals [33]. However, this is the first experimental pilot study showing ECMO's effect on temperature, acidosis, and coagulation in a rabbit model of trauma and hemorrhage. Further studies to evaluate ECMO's role in trauma are needed and indications for VA-ECMO in severe trauma need to be established in collaboration between the trauma communities and ECMO communities.

\section{Conclusions}

VA-ECMO seems beneficial in an experimental traumatic hemorrhagic shock model for stabilization of central hemodynamics, improvement of acidosis, body temperature, and coagulopathy during the initial resuscitation phase. ECMO may increase the likelihood of survival but this need to be confirmed in larger future studies.
Acknowledgements The authors wish to thank ECMO Drs Michael Broomé and Kenneth Palmér, the ECMO technician Christer Eriksson RN, ROTEM expert Gunilla Gryfelt and the animal technician Pellina Jansson for excellent assistance throughout the study. The study was conducted at Karolinska Experimental Research and Imaging Center (KERIC) at Karolinska Institutet, Stockholm, Sweden.

\section{Compliance with ethical standards}

Conflict of interest Magnus Larsson, Pär Forsman, Patricia Hedenqvist, Anders Östlund, Jan Hultman, Agneta Wikman, Louis Riddez, Björn Frenckner, Matteo Bottai, and Carl-Magnus Wahlgren declare that they have no conflict of interest. This study was supported by grants from The Laerdal ${ }^{\circledR}$ Foundation, Kronprinsessan Lovisas Fond För Barnasjukvård and The Carnegie Fund.

Ethical standards The study followed appropriate animal regulatory guidelines and was approved by the Ethics Committee for Experiments in Animals, Karolinska Institutet, Stockholm, Sweden.

Open Access This article is distributed under the terms of the Creative Commons Attribution 4.0 International License (http://creativecommons.org/licenses/by/4.0/), which permits unrestricted use, distribution, and reproduction in any medium, provided you give appropriate credit to the original author(s) and the source, provide a link to the Creative Commons license, and indicate if changes were made.

\section{References}

1. Hoyt DB. A clinical review of bleeding dilemmas in trauma. Semin Hematol. 2004;41(1 Suppl 1):40-3.

2. Sauaia A, Moore FA, Moore EE, Moser KS, Brennan R, Read RA, et al. Epidemiology of trauma deaths: a reassessment. J Trauma. 1995;38(2):185-93.

3. Krug EG, Sharma GK, Lozano R. The global burden of injuries. Am J Publ Health. 2000;90(4):523-6.

4. Peden MM, McGee K, Krug E, World Health Organization. Injuries and Violence Prevention Department. Injury: a leading cause of the global burden of disease, 2000. Geneva: Dept. of Injuries and Violence Prevention, Noncommunicable Diseases and Mental Health Cluster, World Health Organization; 2002;50.

5. Gruen RL, Brohi K, Schreiber M, Balogh ZJ, Pitt V, Narayan M, et al. Haemorrhage control in severely injured patients. Lancet. 2012;380(9847):1099-108.

6. Schreiber MA. Damage control surgery. Crit Care Clin. 2004;20(1):101-18.

7. Hess JR, Brohi K, Dutton RP, Hauser CJ, Holcomb JB, Kluger $\mathrm{Y}$, et al. The coagulopathy of trauma: a review of mechanisms. $\mathrm{J}$ Trauma. 2008;65(4):748-54.

8. Brohi K, Cohen MJ, Ganter MT, Matthay MA, Mackersie RC, Pittet JF. Acute traumatic coagulopathy: initiated by hypoperfusion: modulated through the protein $\mathrm{C}$ pathway? Ann Surg. 2007;245(5):812-8.

9. Wolberg AS, Meng ZH, Monroe DM 3rd, Hoffman M. A systematic evaluation of the effect of temperature on coagulation enzyme activity and platelet function. $\mathrm{J}$ Trauma. 2004;56(6):1221-8.

10. Meng ZH, Wolberg AS, Monroe DM 3rd, Hoffman M. The effect of temperature and $\mathrm{pH}$ on the activity of factor VIIa: implications for the efficacy of high-dose factor VIIa in hypothermic and acidotic patients. J Trauma. 2003;55(5):886-91. 
11. Martini WZ, Pusateri AE, Uscilowicz JM, Delgado AV, Holcomb JB. Independent contributions of hypothermia and acidosis to coagulopathy in swine. J Trauma. 2005;58(5):1002-9 (discussion 9-10).

12. Engstrom M, Schott U, Romner B, Reinstrup P. Acidosis impairs the coagulation: a thromboelastographic study. J Trauma. 2006;61(3):624-8.

13. Bartlett RH. Extracorporeal life support: history and new directions. ASAIO J. 2005;51(5):487-9.

14. Peek GJ, Mugford M, Tiruvoipati R, Wilson A, Allen E, Thalanany MM, et al. Efficacy and economic assessment of conventional ventilatory support versus extracorporeal membrane oxygenation for severe adult respiratory failure (CESAR): a multicentre randomised controlled trial. Lancet. 2009;374(9698):1351-63.

15. Michaels AJ, Schriener RJ, Kolla S, Awad SS, Rich PB, Reickert $\mathrm{C}$, et al. Extracorporeal life support in pulmonary failure after trauma. J Trauma. 1999;46(4):638-45.

16. Arlt M, Philipp A, Voelkel S, Rupprecht L, Mueller T, Hilker M, et al. Extracorporeal membrane oxygenation in severe trauma patients with bleeding shock. Resuscitation. 2010;81(7):804-9.

17. Firstenberg MS, Nelson K, Abel E, McGregor J, Eiferman D. Extracorporeal membrane oxygenation for complex multiorgan system trauma. Case Rep Surg. 2012;2012:897184.

18. Bonacchi M, Spina R, Torracchi L, Harmelin G, Sani G, Peris A. Extracorporeal life support in patients with severe trauma: an advanced treatment strategy for refractory clinical settings. J Thorac Cardiovas Surg. 2013;145(6):1617-26.

19. Guirand DM, Okoye OT, Schmidt BS, Mansfield NJ, Aden JK, Martin RS, et al. Venovenous extracorporeal life support improves survival in adult trauma patients with acute hypoxemic respiratory failure: a multicenter retrospective cohort study. J Trauma Acute Care Surg. 2014;76(5):1275-81.

20. Larsson M, Rayzman V, Nolte MW, Nickel KF, Bjorkqvist J, Jamsa A, et al. A Factor XIIa Inhibitory Antibody Provides Thromboprotection in Extracorporeal Circulation Without Increasing Bleeding Risk. Sci Trans Med. 2014;6(222):222ra17.

21. Favaloro EJ. Laboratory assessment as a critical component of the appropriate diagnosis and sub-classification of von Willebrand's disease. Blood Rev. 1999;13(4):185-204.

22. Wong PC, Crain EJ, Xin B, Wexler RR, Lam PY, Pinto DJ, et al. Apixaban, an oral, direct and highly selective factor Xa inhibitor: in vitro, antithrombotic and antihemostatic studies. $\mathrm{J}$ Thromb Haemost. 2008;6(5):820-9.

23. Huber PJ. The behavior of maximum likelihood estimates under nonstandard conditions. Proceedings of the Fifth Berkeley Symposium on Mathematical Statistics and Probability. Vol. 1. Berkeley: University of California Press; 1967. pp 221-33.

24. Zhao L, Luo L, Chen J, Xiao J, Jia W, Xiao Y. Utilization of extracorporeal membrane oxygenation alleviates intestinal ischemia-reperfusion injury in prolonged hemorrhagic shock animal model. Cell Biochem Biophys. 2014;70(3):1733-40.

25. Park KH, Lee KH, Kim H. Effect of hypothermia on coagulatory function and survival in Sprague-Dawley rats exposed to uncontrolled haemorrhagic shock. Injury. 2013;44(1):91-6.

26. Engstrom M, Schott U, Nordstrom CH, Romner B, Reinstrup P. Increased lactate levels impair the coagulation system-a potential contributing factor to progressive hemorrhage after traumatic brain injury. J Neurosurg Anesthesiol. 2006;18(3):200-4.

27. Jaffer IH, Fredenburgh JC, Hirsh J, Weitz JI. Medical deviceinduced thrombosis: what causes it and how can we prevent it? J Thromb Haemost. 2015;13(Suppl 1):S72-81.

28. Anderson HL 3rd, Cilley RE, Zwischenberger JB, Bartlett RH. Thrombocytopenia in neonates after extracorporeal membrane oxygenation. ASAIO Trans Am Soc Artif Inter Organs. 1986;32(1):534-7.

29. Gorbet MB, Sefton MV. Biomaterial-associated thrombosis: roles of coagulation factors, complement, platelets and leukocytes. Biomaterials. 2004;25(26):5681-703.

30. Larsson M, Talving P, Palmer K, Frenckner B, Riddez L, Broome M. Experimental extracorporeal membrane oxygenation reduces central venous pressure: an adjunct to control of venous hemorrhage? Perfusion. 2010;25(4):217-23.

31. Peek GJ, Firmin RK. The inflammatory and coagulative response to prolonged extracorporeal membrane oxygenation. ASAIO J. 1999;45(4):250-63.

32. Karges HE, Funk KA, Ronneberger H. Activity of coagulation and fibrinolysis parameters in animals. Arzneimittelforschung. 1994;44(6):793-7.

33. Tsukamoto T, Pape HC. Animal models for trauma research: what are the options? Shock. 2009;31(1):3-10. 